\title{
Evaluation of Planned Construction Projects Using Fuzzy Logic
}

\author{
Marcin Gajzler ${ }^{1} \cdot$ Krzysztof Zima $^{2}$
}

Received: 2 May 2016 / Revised: 25 September 2016 / Accepted: 11 December 2016 / Published online: 4 April 2017

(C) The Author(s) 2017. This article is an open access publication

\begin{abstract}
The study presents a model for the evaluation of construction projects from the point of view of the client (e.g. developer company). The problem lies in choosing the best solution from the point of view of many criteria. The proposed model is based on a multi-criteria comparative analysis using fuzzy logic. The first part of the paper presents a selection of criteria describing the construction project along with their description. The set of attributes describing the analysed object was determined on the basis of the synthesis of specific proposals for the parameters of construction projects. The set of criteria has been divided into two groups: technical, technological and organisational criteria and separately the economic criteria. Then, the number of variables describing the observations was checked using principal component analysis (PCA). Course of action was presented in the event of multiple criteria analysis using the fuzzy set theory. Both the weights and the evaluations of individual criteria were modelled using membership functions due to the fact that when describing a construction project, or the validity of the criteria of describing variables, they are approximate. An analysis of the correlation of selected project criteria was presented. The proposed decision support model of assessing a construction project makes possible to compare various variants based on 11 factors identified. The use of fuzzy logic has enabled more accurate description of the phenomenon
\end{abstract}

Krzysztof Zima

kzima@izwbit.pk.edu.pl

1 Faculty of Civil and Environmental Engineering, Poznan University of Technology, Piotrowo 5, 60-965 Poznań, Poland

2 Faculty of Civil Engineering, Cracow University of Technology, Warszawska 24 st., 31-155 Kraków, Poland analysed when the exact parameters of the project in the planning and preparation stage of the project are not known.

Keywords Fuzzy logic - Construction investment · Investment evaluation · Multi-criteria analysis

\section{Introduction}

Evaluation of construction projects is particularly difficult due to their complexity. The difficulty of this issue consists of determining the criteria for the evaluation of the planned construction project, which consists of a number of economic, technical and commercial parameters. A client constructing a building for sale or rent is primarily interested in the cost of construction, the quality and the duration of construction. Despite this, he must also take into account the preferences of future users of the building. Reconciling the client's own interests with that of the user is a difficult task for the client. In the evaluation of a project, we can meet many possible variants of the final implementation of the project. For example, analysing such evaluation criteria as cost, quality and delivery time, we can make a different choice of solutions for the planned project in accordance with each of these criteria. The purpose of the article is to present a comprehensive methodology for evaluating construction projects. The methodology and the evaluation criteria are shown using the example of a project for the construction of residential buildings.

Trying to describe the construction project, it often happens that the values for some variables are approximate and subjective. Construction projects are often described in very vague terms. This is expressed in such statements as "substantially", "good", "almost", etc. For example, in 
describing the location of the project, we can say that: The location is good, or comparing two projects: The location of the building project $\mathrm{A}$ is much better than that of construction project $\mathrm{B}$. Also, assessing the impact of a factor on the proposed project, we can say that: The impact of this factor is almost none. This is partly due to the fact that the experts, in order not to make a mistake, prefer to give answers only in reference to quality, with a certain degree of generalisation. Of course we can interpret such statements and use knowledge formulated in this way to solve problems involving the evaluation of a construction project. However, it is difficult to accurately interpret them. Their vagueness is the cause hindering the sufficiently accurate determination of the value of individual evaluation criteria. The problem lies in the specific determination of what is actually meant when the given expert says the "location is good" or the "location is much better".

The multi-criteria optimisation problem consists of finding the optimal solution, which is kind of a compromise between all the adopted criteria of evaluation of a project. In order to describe approximate (vague) values, methods based on the theory of fuzzy sets are used. Fuzzy logic is very well suited to seek solutions to problems, which include the human element of subjectivity, such as making decisions about choosing the best variant of the planned construction project.

The client should get a clear answer that solution variants are efficient from the point of view of many criteria. The aim of the study should, therefore, be to prioritise the planned variants of solutions from best to worst.

\section{Literature Review}

There have been many attempts to identify the success factors of a construction project. Yong Mustaffa [1] identified 37 factors determining the success of a construction project, of which in their study they distinguished 15 critical factors for the success of a construction project in Malaysia, similarly to Takim and Adnan [2] who have identified 30 such factors. The effectiveness and strategies of a construction project were also investigated, among others in [3-8]. Frequently, factors are highlighted in the literature affecting the cost of construction of a building, for example, in [9-11].

Thomas $\mathrm{Ng}$ et al. [12] on the basis of experience in Hong Kong have developed two modelling approaches: a vector error correction (VEC) and the multiple regression model, and have compared their accuracy with respect to public projects, gross domestic product (GDP) and unemployment rate.

Models supporting decision-making, for example [13], are also created, taking into account the most important criteria for evaluating the effectiveness of a construction project.

Zavadskas et al. [14] have used one of the methods of multi-criteria analysis ELECTRE III for the evaluation of a construction project from the point of view of many criteria. Šarka et al. [15] used a multi-criteria comparative analysis in the evaluation of public investment, and Ustinovichius and Šarkienė [16] applied mathematical methods in the assessment of construction projects involving the construction of apartment buildings.

The concept and the mathematical tool of the fuzzy set theory proposed by Zadeh [17] have become very popular. The task of multi-criteria evaluation in the conditions of non-statistical uncertainty, often using linguistic expressions, is very effectively formulated using the theory invented by Zadeh. Thus, methods have been created, which employ optimisation methods using the fuzzy sets theory. An example may be the method used by Baas-Kwakernaak [18], showing both the evaluation criteria and their validity in fuzzy form. Based on the theory of fuzzy sets, Guneri et al. [19] described the use of the fuzzy analytic network process (fuzzy ANP) to choose the best location of a shipyard. Zima [20] presented an example of estimating costs in the early phase of the project using fuzzy case-based reasoning and Kaveh et al. [21] used two metahuristic algorithms for solving fuzzy resource allocation project scheduling problem.

Risk factors, similarly to individual types of cost, may be ascribed to subsequent stages of a building's life cycle [22]. Minasowicz [23] presented the NPV analysis and the investment risk analysis at the stage of strategy assessment and the feasibility study. Analysis of the value of a project allowing for the specification of the probability of a given value of cash flows and NPV was also carried out with the use of the fuzzy set theory. Chen [24] proposes a hybrid knowledge-sharing model that integrates the concepts of self-organisation of the optimisation function, fuzzy logic control and hyper-rectangular composite neural networks, in order to answer the question of whether to perform or refrain from construction projects carried out by foreign companies. The study was based on 520 quarterly financial reports of all construction companies operating in Taiwan. Nasirzadeh et al. [25] proposed model accounts for both the client and the contractor costs using cooperative-bargaining game model for quantitative risk allocation to perform the quantitative risk allocation process.

There have also been attempts of mathematical modelling of the quality management process in the construction project [26], integrated design management system (IDMS) [27] or even assessment of a conceptual cost estimation [10]. 


\section{Evaluation Model for a Construction Project Using Fuzzy Logic}

Decision problem faced by a client to choose the optimal variant of the solution of the planned development project in the housing sector. The proposed model for the assessment of the building project uses elements of fuzzy logic. The adopted course of action is illustrated in Fig. 1 and briefly characterised in the following sections.

\subsection{Determining the Object and Purpose of the Analysis}

The main task is to describe the analysed object in detail. Determining the analysed object is to indicate the studied object and provide its characteristics (a set of attributes describing the analysed object). The analysed object is therefore a construction project, involving the implementation of a multi-family residential building intended for sale. The aim of the analysis is a certain final state of the designed object assumed in the course of the study, in this case distinguishing from the analysed set the best solution or a subset of a number of sufficiently good solutions, or prioritising these solutions from best to worst.

\subsection{Determination of an Initial Set of Criteria}

A decisive action in regard to the correctness of the analysis is determining the elements of the initial set of criteria explaining the analysed object. This set should contain all the variables fully representing the characteristics of the designed object. The set of attributes that describe the analysed object was determined on the basis of the synthesis of specific proposals for the parameters of construction projects. The initial set of criteria has been divided into those that describe technical, technological and organisational criteria, as well as customer preferences and those describing the economic criteria. A detailed analysis of the economic criteria has been carried out separately.

A descriptive model showing the dependence of the analysed object on the explanatory variables (characteristics of the analysed object) in general form can be written as:

$Y=f\left(x_{1}, x_{2}, \ldots, x_{k}, \epsilon\right), k=1,2, \ldots, n$.

where $Y$ analysed object; $x_{1}, x_{2}, \ldots, x_{k}$ characteristics of the analysed object (explanatory criteria); $\varepsilon$ random deviation (sum of partial random deviations $\varepsilon_{1}, \varepsilon_{2}, \ldots, \varepsilon_{k}$ ); $n$ number of finally adopted criteria for evaluating the variants of a construction project; $f$ analytical form of the function of
Fig. 1 Evaluation model for variants of a construction project using fuzzy logic

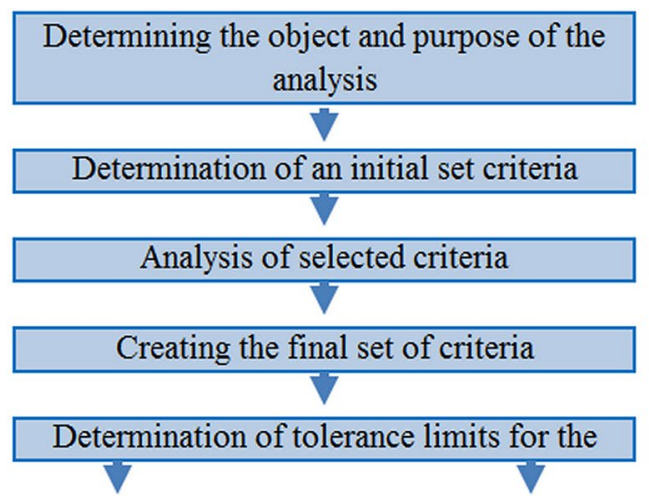

\begin{tabular}{|l|}
\hline $\begin{array}{l}\text { Determination of the validity for } \\
\text { technical and operational criteria }\end{array}$ \\
\hline Comparative analysis of variants \\
\hline Defuzzification of variants \\
\hline
\end{tabular}

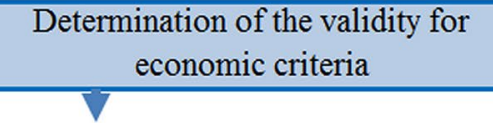

Comparative analysis of variants

Defuzzification of variants

Comparison of solutions

Prioritising variants 
explanatory criteria, which is determined during the construction of the model.

The inclusion of all explanatory variables in the model is impossible. Therefore, random deviations arise from a limited number of variables used in the model. The better the model reflecting the reality, the less random are the deviations. Introduction of hierarchical coefficients (weights) corresponding to each of the evaluation criteria will, however, cause the assignment of partial random deviations to individual criteria.

\subsection{Analysis of Selected Criteria}

The initially accepted set of criteria is a set with several elements, which significantly hinders the process of comparative analysis. With such a large collection of input data, it could be that a part of the data would be difficult to determine in the planning and preparation of a construction project, and a part of the evaluation criteria would have a too small significance for the overall assessment of the construction project. This implies the need to reduce the initial set of explanatory variables. The initially adopted set of explanatory variables will be analysed in terms of [28]:

- informational capacity,

- mutual relationship between the explanatory variables,

- level of detail of the description,

- level of variation (in order to eliminate variables characterised by too low level of variation).

In order to reduce the initial set of criteria, a matrix of arcs of the criteria graph $G(n+1, n+1)$ was built, where $\mathrm{n}$ is the number of explanatory variables (criteria) and the additional element " $n+1$ " is the so-called global criterion, connected to each of the " $n$ " criteria by arcs directed to each criterion. The introduction of a global criterion causes a consistency of criteria graphs, conditioning the use of the following calculation algorithm. Explanatory variables (criteria) are analysed in terms of information capacity. If in the analysed pair of criteria, information on the object of study overlaps at least in part, the relationship between the criteria is studied, defining the direction of this relationship. In this case for the pair of criteria $K_{i}, K_{j}$, if $K_{j}$ includes a part or all of the information of $K_{i}$, the element of the matrix of arcs of the graph of criteria $G(j, i)$ is assigned the value of 1 , and the element $G(i, j)$ the value of 0 . If the information contained in the criteria $K_{i}, K_{j}$ is independent, both elements $G(i, j)$ and $G(j, i)$ are assigned the value of 0 . After the construction of the matrix $G(n+1, n+1)$, we should be able to arrange the resulting graph of criteria in layers. For the resulting matrix $G=\left\{g_{i j}\right\}$, we calculate:

$b_{j}^{0}=\sum_{i=1}^{n+1} g_{i j}$

$b_{j}^{0}$ number of arcs entering the $j$ th vertex.

If for the vertex $K_{j}, b_{j}^{0}=0$, then vertex $K_{j}$ assumes the order of 0 .

Then we calculate in sequence:

$$
\begin{aligned}
& b_{j}^{k} \quad \text { for } j=1, \ldots, n+1 ; \quad k=1, \ldots, r \\
& \text { and } b_{j}^{k-1}= \begin{cases}0 \text { when } & b_{j}^{k-1}=0 \\
b_{j}^{k-1}-\sum_{i=Z_{k-1}} g(i, j) & \text { when } \quad b_{j}^{k-1} \neq 0\end{cases}
\end{aligned}
$$

$Z_{k-1}$ set of vertices, for which $b_{j}^{k}=0$, assign the vertices of the $k$ th order.

The analysis is completed at the moment of the assignment of all the criteria to the individual layers.

\begin{tabular}{|c|c|c|}
\hline Criterion & Criterion description & Valuation type \\
\hline Distance from the city centre & Distance from a fixed point in the city centre & Destimulant \\
\hline Immediate environment & External factors influencing the increase/decrease of property value & Stimulant \\
\hline Housing structure & $\begin{array}{l}\text { Determines the client's offer compatibility with the current demand in the market, the determi- } \\
\text { nation of the criteria value is dependent on the statistics of the current structure of the sale }\end{array}$ & Nominant \\
\hline Floorage use ratio & Ratio of living area to floorage of a civil structure & Stimulant \\
\hline Design solutions & Evaluation of design solutions, the applied technologies and materials & Stimulant \\
\hline Land-use ratio & Ratio of a footprint area to a plot area & Stimulant \\
\hline Modishness (trend) & $\begin{array}{l}\text { Evaluation of the attractiveness of the location from the point of view of the social environment } \\
\text { of a project }\end{array}$ & Stimulant \\
\hline Scheduled execution time ratio & Ratio of the scheduled execution time to the building volume & Destimulant \\
\hline Building layout & $\begin{array}{l}\text { Shape of the building defined as the ratio of the circumference of the outer walls to the area } \\
\text { obtained from the building view }\end{array}$ & Nominant \\
\hline Number of storeys & Defines the height of the building, depends on the legal constraints (Zoning decision) & Nominant \\
\hline Additional offer & Factors affecting attractiveness of the offer & Stimulant \\
\hline
\end{tabular}

Table 1 Final set of criteria describing the construction project in the housing sector 
The coefficients of variation for individual criteria have also been determined, so that the criteria that will be considered as quasi-fixed (have too little variability) will be eliminated from the set of explanatory variables, due to their unsuitability in terms of the impact on the global result of the evaluation of a construction project.

\subsection{Creating the Final Set of Criteria}

The set of criteria resulting from prior analysis of criteria describing the object of multi-criteria evaluation should be sufficiently complete and representative. The final set of criteria specified in this way completes the initial part of the analysis (Table 1).

Due to the type of valuation, the nature of the individual criteria is specified in Table 1. The type of stimulant evaluation is specified by a criterion, whose higher value also causes a higher global assessment of the analysed variant of the solution. Destimulant is a criterion whose increase results in the deterioration of the global assessment of the analysed variant of the solution. Nominant is the criterion for which the values falling within a prescribed range, or equal to a certain value, indicate the maximum assessment of the given solution, and any deviations - both upward and downward-lower the global assessment of the solution variant analysed.

Using the analysis of main components, the number of variables describing the observations was checked. The correlation between the variables occurring in the data set was determined. Variables should be the least correlated with each other. The procedure for the determination of the main components is as follows:

1. The correlation matrix of the input data set $R_{x x}$ is determined.

2. The eigenvalues $\lambda_{i} i$ and eigenvectors $w_{i}$ of the correlation matrix are determined.

3. The eigenvalues are ranked from largest to smallest.

4. The matrix $W=\left[w_{1}, w_{2}, \ldots, w_{i}\right]^{T}$ for the PCA transformation and the diagonal matrix $L=\operatorname{diag}\left[\lambda_{1}, \lambda_{2}, \ldots . \lambda_{i}\right]$ are determined.

5. The main components described in the equation $y_{i}=w_{i}^{T} x_{i}$ are determined.

6. The relative contribution of each of the main components into the total variance of the data is calculated, according to the formula:

$m_{i}=\frac{\lambda_{i}}{\sum_{j=1}^{k} \lambda_{j}}$, gdzie $\quad j=1,2, \ldots, k$

Analysing selected 11 criteria for assessing the development project, matrix of correlation $\mathrm{R}_{\mathrm{xx}}$ was decomposed according to eigenvalues. This provided the eigenvalues (sorted in descending order), as well as their associated eigenvectors forming the matrix $W=\left[w_{1}, w_{2}, \ldots, w_{11}\right]$ of the PCA transformation and the diagonal matrix L composed of the eigenvalues $\lambda_{1}, \lambda_{2}, \ldots \lambda_{11}$ of the correlation matrix for the set of input data $R x x$.

Main components take the following form:

$$
\begin{aligned}
& y_{1}=-0.2838 \times X_{1}+0.0097 \times X_{2}+0.4006 \times X_{3}+0.1202 \\
& \times X_{4} 0.6072 \times X_{5}+0.3521 \times X_{6}-0.2055 \\
& \times X_{7}+0.0467 \times X_{8}+0.0154 \times X_{9}+0.1731 \times X_{10}-0.4209 \times X_{11} \\
& y_{2}=-0.6210 \times X_{1}+0.1142 \times X_{2}+0.0712 \times X_{3}-0.0094 \\
& \times X_{4}+0.2365 \times X_{5}-0.1990 \times X_{6}+0.3705 \\
& \times X_{7}-0.2160 \times X_{8}+0.0101 \times X_{9}-0.4040 \times X_{10}-0.3917 \times X_{11} \\
& y_{3}=-0.0599 \times X_{1}-0.3318 \times X_{2}-0.5789 \times X_{3}+0.1235 \\
& \times X_{4}-0,1502 \times X_{5}+0.0045 \times X_{6}-0.0276 \\
& \times X_{7}+0.4003 \times X_{8}-0.4901 \times X_{9}-0.1662 \times X_{10}-0.2909 \times X_{11} \\
& y_{4}=+0.2897 \times X_{1}+0.5577 \times X_{2}+0.0626 \times X_{3}+0.2240 \\
& \times X_{4}+0.1528 \times X_{5}-0.2358 \times X_{6}+0.1410 \\
& \times X_{7}+0.4897 \times X_{8}+0.0911 \times X_{9}+0.1905 \times X_{10}-0.4095 \times X_{11} \\
& y_{5}=-0.2278 \times X_{1}+0.0473 \times X_{2}+0.1221 \times X_{3}+0.3133 \\
& \times X_{4}+0.0090 \times X_{5}-0.5619 \times X_{6}-0.6844 \\
& \times X_{7}+0.0405 \times X_{8}-0.0501 \times X_{9}-0.1418 \times X_{10}+0.1558 \times X_{11} \\
& y_{6}=-0.2170 \times X_{1}+0.4007 \times X_{2}-0.3833 \times X_{3}+0.2943 \\
& \times X_{4}-0.2043 \times X_{5}+0.3436 \times X_{6}+0.0100 \\
& \times X_{7}+0.1612 \times X_{8}+0.3807 \times X_{9}-0.3240 \times X_{10}+0.3507 \times X_{11} \\
& y_{7}=+0.1338 \times X_{1}+0.1309 \times X_{2}-0.4014 \times X_{3}+0.3101 \\
& \times X_{4}-0.3339 \times X_{5}-0.2817 \times X_{6}+0.1295 \\
& \times X_{7}-0.6266 \times X_{8}+0.0156 \times X_{9}+0.2928 \times X_{10}-0.1464 \times X_{11} \\
& y_{8}=-0.3456 \times X_{1}-0.1169 \times X_{2}-0.3613 \times X_{3}-0.4344 \\
& \times X_{4}+0.0575 \times X_{5}-0.1484 \times X_{6}-0.1829 \\
& \times X_{7}+0.1668 \times X_{8}+0.4984 \times X_{9}+0.4402 \times X_{10}-0.1375 \times X_{11} \\
& y_{9}=-0.3157 \times X_{1}+0.5288 \times X_{2}-0.0649 \times X_{3}-0.3031 \\
& \times X_{4}-0.0110 \times X_{5}+0.0625 \times X_{6}-0.0236 \\
& \times X_{7}-0.0214 \times X_{8}-0.5934 \times X_{9}+0.3146 \times X_{10}+0.2616 \times X_{11} \\
& y_{10}=-0.0220 \times X_{1}+0.0407 \times X_{2}-0.1393 \times X_{3}+0.2815 \\
& \times X_{4}+0.5939 \times X_{5}+0.4910 \times X_{6}-0.3839 \\
& \times X_{7}-0.2521 \times X_{8}-0.0487 \times X_{9}+0.1546 \times X_{10}+0.3047 \times X_{11} \\
& y_{11}=-0.3313 \times X_{1}-0.3014 \times X_{2}+0.1356 \times X_{3}+0.5285 \\
& \times X_{4}+0.1416 \times X_{5}-0.0254 \times X_{6}+0.3649 \\
& \times X_{7}+0.1974 \times X_{8}-0.0236 \times X_{9}+0.4642 \times X_{10}+0.3047 \times X_{11}
\end{aligned}
$$

After calculation, the relative contribution of each of the main components into the total variance of the tested sample is therefore: $m_{1}=0,2024 ; m_{2}=0,1523 ; m_{3}=0,1312$; $m_{4}=0,1162 ; \quad m_{5}=0,1122 ; \quad m_{6}=0,0758 ; \quad m_{7}=0,0753 ;$ $m_{8}=0,0452 ; m_{9}=0,0394 ; m_{10}=0,0337 ; m_{11}=0,0164$. 
The largest principal component obtained for the sample shows only $20.24 \%$ of participation in the total variance of the data. The percentage cumulative participation of the first five values is only $71.42 \%$, and the first eight values $91.05 \%$ of participation in the total variance of the data. Adoption of only the first few criteria for the evaluation of the project may result in a large error in the approximation of results.

All the analysed criteria satisfy the basic requirements of a linear econometric model. The analysed criteria have a sufficiently high variability and are poorly correlated with each other, and the individual criteria are strongly correlated with other criteria which are not criteria of the evaluation they represent, and are also sufficiently correlated with the global evaluation of the project.

\subsection{Determination of Tolerance Limits for the Criteria}

Analysing the various available solution variants for the construction project or variants for carrying out different projects, we must pre-eliminate those for which even a single explanatory variable does not meet the requirements. Therefore, for the individual variables (if possible) we must determine the minimum and maximum values that a variable can take. Exceeding these values will eliminate the variant or will lead to its correction already in the initial stage of the analysis.

\subsection{Determination of the Validity Criteria}

The proposed calculation algorithm enables the decisionmaker (the client) to determine their own, subjective weights, but in the created model we will use the calculation of hierarchical coefficients by expert evaluation using the pairwise comparison matrix. A pairwise comparison matrix is a square matrix allowing, on the basis of the comparison criteria in pairs, to determine the coefficients of the relative importance of each of them. When filling out the matrix, linguistic assessment tables are used. The process of filling out the table consists of asking the expert to compare in order the validity of all pairs of criteria, e.g. "What is the relation of the validity of criterion $x$ to criterion $y$ ?". To which the expert responds in accordance with the five-point linguistic assessments table:

- Equally important (numerical value -1).

- Moderately more important (numerical value -2 ).

- More important (numerical value -3).

- Much more important (numerical value -4).

- Definitely more important (numerical value -5 ).

After filling out the matrix of comparisons, the weights for each criterion are calculated. The size of individual weights can be calculated using, for example, the arithmetic mean method, and then by standardising the coefficients. The overall validities of the criteria given by $\mathrm{P}$ experts are modelled using triangular membership functions (Fig. 2).

The values of characteristic points for determining the validity of the criteria are set, for example, by a group of experts. Characteristic points of the triangular membership function are determined as follows:

$v_{i}(\min )=\min v_{i j}$

$v_{i}($ average $)=\frac{1}{P} \sum_{j=1}^{P} v_{i j}$

$v_{i}(\max )=\max v_{i j}$

where $v_{i j}$ standardised assessment of the validity of the $i$ th criterion carried out by the $j$ th expert; $P$ number of experts making the evaluation.

Table 2 summarises the assessment criteria weights, as well as the adopted shapes of the membership function and characteristic points. The shapes of the membership function and characteristic points were determined on the
Fig. 2 Characteristic points of the triangular membership function [28]

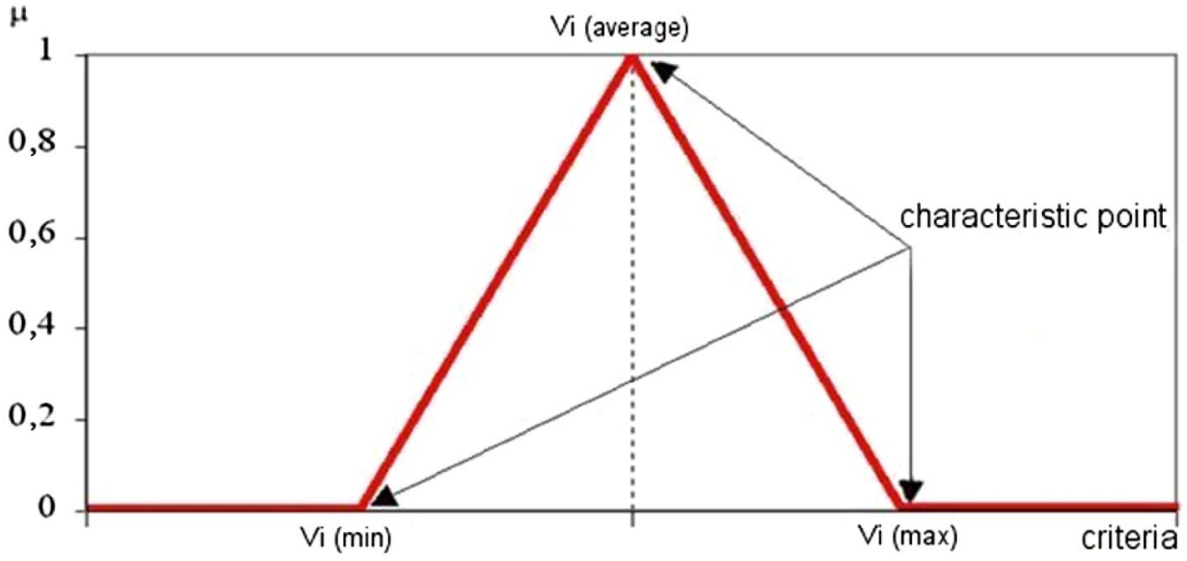


Table 2 Shapes and characteristic points of the membership function for individual criteria

\begin{tabular}{|c|c|c|c|c|}
\hline Criterion & $\begin{array}{l}\text { Weight of crite- } \\
\text { rion }(\%)\end{array}$ & $\begin{array}{l}\text { Shape of membership } \\
\text { function }\end{array}$ & Function formula & Characteristic points \\
\hline Distance from the city centre & 16.02 & Shape class $\gamma$ & $\mu(x)=\left\{\begin{array}{c}0 \text { for } x \leqslant a \\
\frac{x-a}{b-a} \text { for } a<x<b \\
1 \text { for } x \geqslant b\end{array}\right.$ & $\begin{array}{l}a=1 \\
b=5\end{array}$ \\
\hline Immediate environment & 14.51 & Trapeze shape & $\mu(x)=\left\{\begin{array}{l}0 \text { for } x \leqslant a i x \geqslant d \\
\frac{x-a}{b-a} \text { for } a<x<b \\
\frac{x-d}{c-d} \text { for } c<x<d \\
1 \text { for } b \leqslant x \leqslant c\end{array}\right.$ & $\begin{array}{l}a=1 \text { storey } \\
b=4 \text { storey } \\
c=5 \text { storey } \\
d=17 \text { storey }\end{array}$ \\
\hline Housing structure & 11.55 & Shape class $\gamma$ & $\mu(x)=\left\{\begin{array}{c}0 \text { for } x \leqslant a \\
\frac{x-a}{b-a} \text { for } a<x<b \\
1 \text { for } x \geqslant b\end{array}\right.$ & $\begin{array}{l}a=1 \\
b=5\end{array}$ \\
\hline Floorage use ratio & 9.70 & Shape class $\gamma$ & $\mu(x)=\left\{\begin{array}{c}0 \text { for } x \leqslant a \\
\frac{x-a}{b-a} \text { for } a<x<b \\
1 \text { for } x \geqslant b\end{array}\right.$ & $\begin{array}{l}a=1 \\
b=3\end{array}$ \\
\hline Design solutions & 9.57 & Shape class L & $\mu(x)=\left\{\begin{array}{c}1 \text { for } x \leqslant a \\
\frac{b-x}{b-a} \text { for } a<x<b \\
0 \text { for } x \geqslant b\end{array}\right.$ & $\begin{array}{l}a=2 \mathrm{~km} \\
b=10 \mathrm{~km}\end{array}$ \\
\hline Land-use ratio & 7.62 & Shape class L & $\mu(x)=\left\{\begin{array}{c}1 \text { for } x \leqslant a \\
\frac{b-x}{b-a} \text { for } a<x<b \\
0 \text { for } x \geqslant b\end{array}\right.$ & $\begin{array}{l}a=4.24 \\
b=7\end{array}$ \\
\hline Modishness (trend) & 7.10 & Shape class $\gamma$ & $\mu(x)=\left\{\begin{array}{c}0 \text { for } x \leqslant a \\
\frac{x-a}{b-a} \text { for } a<x<b \\
1 \text { for } x \geqslant b\end{array}\right.$ & $\begin{array}{l}a=1 \\
b=4.5\end{array}$ \\
\hline Scheduled execution time ratio & 6.80 & Trapeze shape & $\mu(x)=\left\{\begin{array}{l}0 \text { for } x \leqslant a i x \geqslant d \\
\frac{x-a}{b-a} \text { for } a<x<b \\
\frac{x-d}{c-d} \text { for } c<x<d \\
1 \text { for } b \leqslant x \leqslant c\end{array}\right.$ & $\begin{array}{l}a=18 \mathrm{~m}^{2} \text { usable area } \\
b=50 \mathrm{~m}^{2} \text { usable area } \\
c=55 \mathrm{~m}^{2} \text { usable area } \\
\mathrm{d}=150 \mathrm{~m}^{2} \text { usable area }\end{array}$ \\
\hline Building layout & 5.94 & Shape class L & $\mu(x)=\left\{\begin{array}{c}1 \text { for } x \leqslant a \\
\frac{b-x}{b-a} \text { for } a<x<b \\
0 \text { for } x \geqslant b\end{array}\right.$ & $\begin{array}{l}a=0.04 \text { day } / \mathrm{m}^{3} \\
b=0.20 \text { day } / \mathrm{m}^{3}\end{array}$ \\
\hline Number of storeys & 5.73 & Shape class $\gamma$ & $\mu(x)=\left\{\begin{array}{c}0 \text { for } x \leqslant a \\
\frac{x-a}{b-a} \text { for } a<x<b \\
1 \text { for } x \geqslant b\end{array}\right.$ & $\begin{array}{l}a=0.63 \\
b=0.85\end{array}$ \\
\hline Additional offer & 5.46 & Shape class $\gamma$ & $\mu(x)=\left\{\begin{array}{c}0 \text { for } x \leqslant a \\
\frac{x-a}{b-a} \text { for } a<x<b \\
1 \text { for } x \geqslant b\end{array}\right.$ & $\begin{array}{l}a=0.2 \\
b=0.3\end{array}$ \\
\hline
\end{tabular}

basis of own research in the Polish market for multi-family housing, research of customer preferences and experts' evaluations.
In the case of economic criteria considered separately, the analysis concerns the two most commonly used indicators NPV and IRR. The choice of characteristic points of 
the NPV criterion consists of determining two characteristic points: limit value $\mathrm{NPV}_{\text {min }}=0$, dividing the planned projects into profitable and unprofitable ones, and $\mathrm{NPV}_{\max }$, which corresponds fully to the expectations of the client (the value corresponding to $30 \%$ of the value of the project was determined). Assuming this value, we used our own surveys of the actual achieved by companies operating in the housing sector in Poland.

The surveys conducted by the author show that $46 \%$ of construction companies in the housing sector in Poland determined the actual value of the IRR achieved within the range of $15-20 \%$. On the other hand, only $4 \%$ of the surveyed companies determined the value of the IRR achieved as less than 5\% and more than $30 \%$. The first characteristic point adopted is the value of $I_{R R}$ min $=5 \%$, and the second characteristic point is $\mathrm{IRR}_{\max }=20 \%$.

Assessment of the different variants has been carried out, adopting the assessment criteria for the NPV and IRR criteria in the class $\gamma$.

\subsection{Comparative Analysis of Variants}

Both the weight and the assessment of individual criteria were modelled using the membership function. Assuming that the values of the evaluations of solutions and the validities of criteria are standardised and defined in the range $[0,1]$, the replacement criterion value for each variant of the solution is a fuzzy number. It can be described using a membership function according to the formula:

$\mu_{Z k}(Z k)=\frac{\sum_{i=1}^{m}\left(\mu_{V_{i}}\left(v_{i}\right) \cdot \mu_{K_{i}}\left(K_{i}\right)\right)}{\sum_{i=1}^{m} \mu_{V_{i}}\left(v_{i}\right)}$

which according to the general principles of operations on fuzzy numbers leads to the relationship:

$\mu_{Z k}(Z k)=\sup \min \left[\min _{i=1, \ldots, m} \mu_{V_{i}}\left(v_{i}\right), \min _{i=1, \ldots, m} \mu_{K_{i}}\left(K_{i}\right)\right]$

for

Fig. 3 Triangular membership function and its decomposition into $\alpha$-sections [28]
$Z_{k}=\frac{\sum_{i=1}^{m}\left(v_{i} \cdot K_{i}\right)}{\sum_{i=1}^{m} v_{i}}$

where $\mu\left(v_{i}\right)$ membership function for the validity of criteria; $\mu\left(K_{i}\right)$ membership function for the assessment of the solution variant according to the $i$ th criterion.

To benefit directly from the above relationship is not simple; hence, simplified methods of carrying out operations on fuzzy numbers are applied, using $\alpha$-sections of fuzzy sets (Fig. 3). The value of the evaluation of solution variants can be determined by converting fuzzy evaluations of solution variants for individual criteria in relation to the corresponding value functions.

Each of the variants of the construction project is evaluated according to the previously selected criteria. With these assumptions, we define the value of the replacement criterion for each of the variants of solutions from set $A$, as the fuzzy number with the membership function:

$\tilde{Z}\left(A_{k}\right)=\mu_{Z k}\left(z_{k}\right)=\mu_{W k i}\left(w_{k i}\right) \times \mu_{v i}\left(v_{i}\right) ; z_{k} \in[0,1]$,

where $\mu_{W k i}\left(w_{k i}\right)$ membership function for the criterion; $\mu_{v i}\left(v_{i}\right)$ membership function for the weights of the criterion.

As a result of such procedure, we get the fuzzy evaluation of the replacement criterion assigned to each project variant.

\subsection{Defuzzification of Variants}

The aim of the analysis is to prioritise solutions from best to worst, assuming that the client expects precise information on the evaluation of the analysed solution variants of the proposed construction project. For this purpose, it is necessary to "sharpen" (defuzzify) the analysed variants according to the relationship:

\section{into $\alpha$-sections [28]}

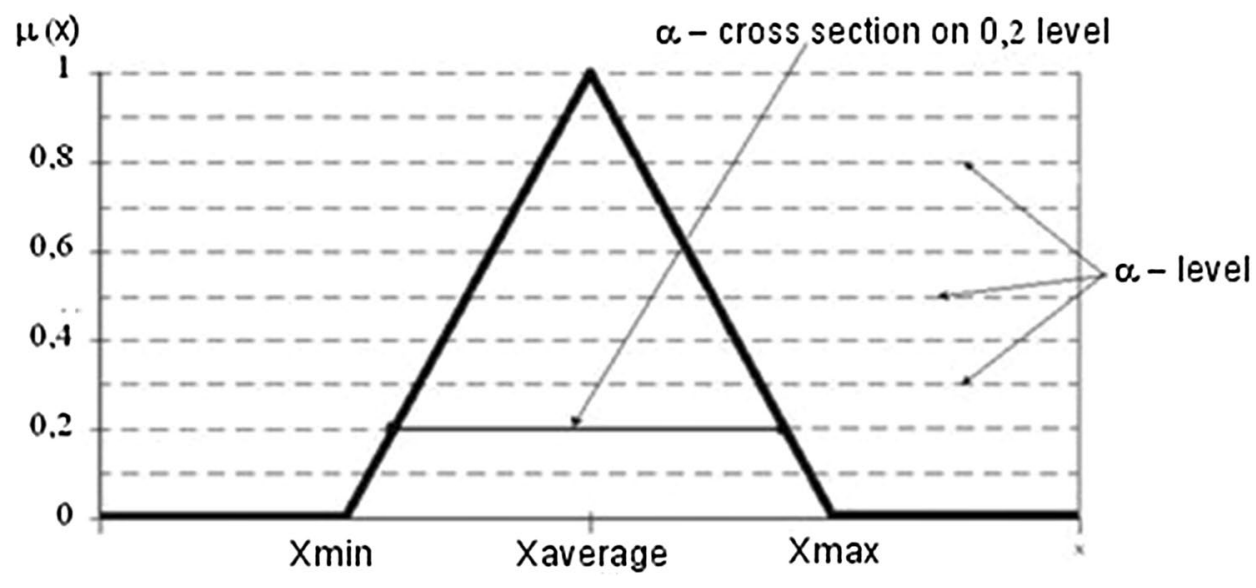




$$
Z_{k}\left(A_{k}\right)=\frac{\int_{0}^{1} z \times \mu_{Z k}\left(z_{k}\right) \times \mathrm{d} z}{\int_{0}^{1} \mu_{Z k}\left(z_{k}\right) \times \mathrm{d} z}
$$

For this purpose, the method of centre of gravity can be used, assigning a real number to the fuzzy number. This value determines the centre of gravity of the area below the graph of the membership function for the given replacement criterion $Z_{k}$.

The centre of gravity method consists in determining the centre of gravity of the area below the graph of the membership function.

A graphical example of the result of determining the centre of gravity $F_{c}$ as the sum of the individual centres of gravity $F x_{i}$ designated for subsequent trapezoidal areas designated by the $\alpha$-sections of the sample membership function for replacement criterion $Z_{k}$ is shown in Fig. 4.

Analysis of economic criteria is similar to the analysis of technical criteria. It will be restricted to the analysis of the basic methods of assessing the effectiveness of the project-NPV and IRR.

Having defined two specific criteria, we can define a replacement criterion:

$D=\min \left[\mu(\mathrm{NPV})^{\alpha_{1}}, \mu(\mathrm{IRR})^{\alpha_{2}}\right]$

where $\alpha_{1}, \alpha_{2}$ weights of individual criteria; $\mu(\mathrm{NPV}), \mu$ (IRR) membership functions for the assessment of criteria NPV and IRR.

Sharpening the resulting fuzzy set is also achieved using the centre of gravity method.

\subsection{Comparison of Solutions}

Sharpened values for both the technical and operational criteria and economic criteria for the individual variants are compared in a chart. For example, variant $\mathrm{A}$ has a higher rating because of the expected profits of 0.8 (variant $\mathrm{B}$ -0.7 ), but the evaluation of the project in terms of the technical and operational criteria is lower for variant $A(0.4)$ than for variant $B(0.5)$. Despite the expected higher profits for variant $A$, there is a greater risk of mismatch of the offer to the market conditions (and thus the risk of not selling all apartments), but there are also more opportunities to improve individual technical indicators.

\subsection{Prioritising Variants}

Prioritising projects from best to worst in the model, the following scale was proposed:

a. For economic criteria- $[0 ; 0.2]$ project is unprofitable; $(0.2 ; 0.4]$ project is little profitable, $(0.4 ; 0.6]$ project is moderately profitable $(0.6 ; 0.8]$ project is very profitable, $(0.8,1]$, project is highly profitable.

b. For technical and operational criteria $-[0,0.2]$ project is very badly planned; $(0.2 ; 0.4]$ project is badly planned; $(0,4 ; 0,6]$ project is moderately planned; $(0.6$; $0.8]$ project is well planned; $(0.8,1]$ project is very well planned.

Project variants can be ranked from best to worst variant, or the best variant can be highlighted and adopted for completion.
Fig. 4 Fuzzy interval, its decomposition into $\alpha$-sections and the location of the centres of gravity for the sample solution variant of the planned construction project

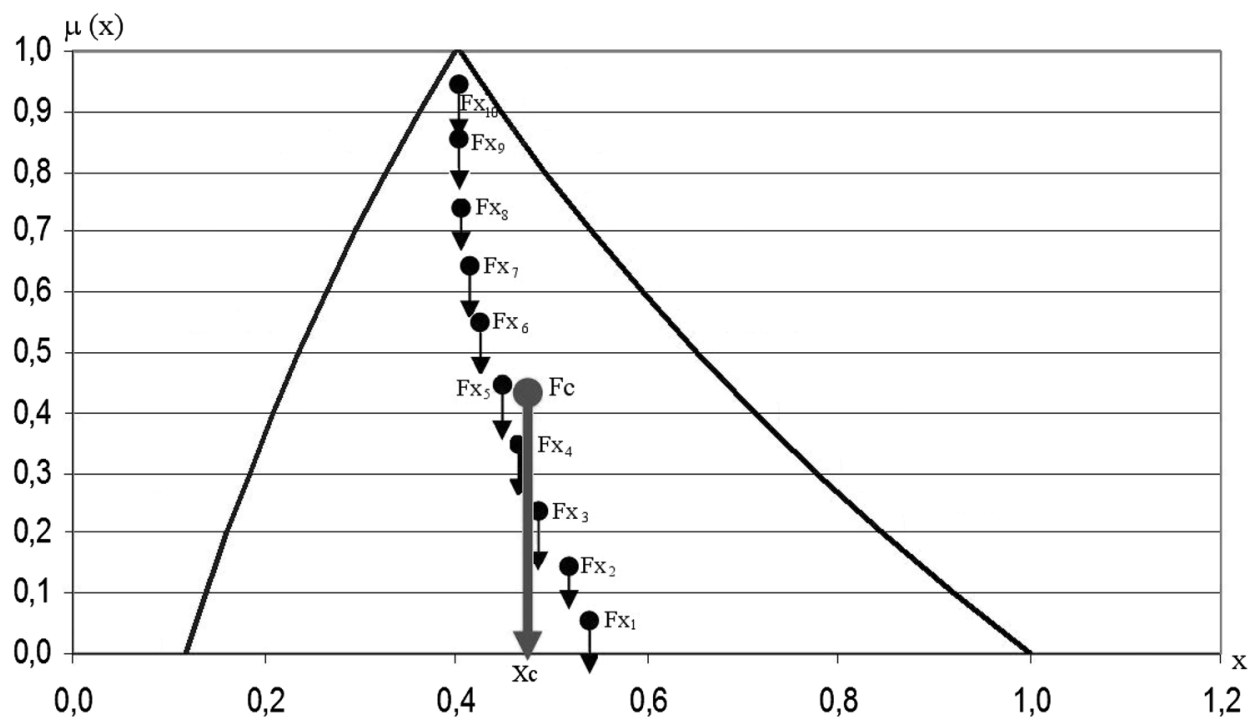




\section{Correlation Analysis of Selected Investment Criteria}

The main problem is determining whether there is any relationship between the variables and whether it is more or less accurate. Analysing the correlation relationship between the studied attributes, it is necessary to prepare scatter plots that show the relationship between the variables graphically.

In the example, the correlations between the criteria were examined. The size of the analysed group is $N=41$ of construction projects carried out in Kraków in the multifamily housing sector. Before the correlation analysis, it was examined whether the criteria selected for analysis have sufficient variability. The critical value of the variation coefficient $v^{*}=0.1$ was adopted. The calculated values of the variation coefficient are shown in Table 3.

All variation coefficients calculated for individual criteria are greater than the critical value $v^{*}$ and therefore are used in further analysis.

The strength of the interdependence of two variables was calculated using Pearson's correlation coefficient, marked $r_{X Y}$, which adopts the values in the range [-1]. Analysis of correlation coefficients by this method requires that the tested variables have normal distributions. It is known, however, that this particular method to a large extent is "resistant" to the deviations of distributions of the variables tested from the normal distribution. Therefore, this method is used, although it can be demonstrated that a number of variables do not have normal distribution. A point of view was adopted that although the variables do not have a strictly normal distribution, their distribution is sufficiently close to it.

The resulting correlation matrix is presented in Table 4. Based on the literature, the author described the level of significance $\alpha=0.05$. The value of the confidence level is therefore equal to $p=95 \%$. As is clear from the data presented in Table 4, the majority of pairs of the calculated correlations determine the strength of the interdependence as faint or weak. Only the pairs of criteria $2-9 ; 2-11 ; 4-8$ determine the correlation between the two variables as average.

It was attempted to analyse the reasons that cause the average correlation in the aforementioned pairs of evaluation criteria. Scatter diagrams were used for this purpose. These diagrams were prepared for all pairs of criteria and did not show significant correlations between the criteria. Here the author presents an example of a scatter diagram for a pair of criteria, for which the strength of correlation is greater than 0.3 .

The strength of correlation between the criteria 2 and 9 is -0.41 and has been described as average. Analysing Fig. $5 \mathrm{a}$, it can be seen that there are two extreme values
Table 3 Variation coefficients of evaluation criteria for the development project

\begin{tabular}{lllllllllllll}
\hline & \multicolumn{1}{l}{ Criterion } \\
\cline { 2 - 11 } & 1 & 2 & 3 & 4 & 5 & 6 & 7 & 8 & 9 & 10 & 11 \\
\hline Arithmetic average & 1.75 & 5.27 & 3.20 & 2.27 & 4.71 & 5.29 & 4.01 & 60.36 & 0.09 & 0.73 & 0.25 \\
Deviation & 1.12 & 2.70 & 1.10 & 0.74 & 1.18 & 0.72 & 0.45 & 32.00 & 0.10 & 0.13 & 0.10 \\
Coefficient of variation $v_{i}$ & 0.64 & 0.51 & 0.34 & 0.33 & 0.25 & 0.14 & 0.11 & 0.53 & 1.19 & 0.18 & 0.40 \\
\hline
\end{tabular}

Table 4 The correlation matrix $R_{x x}$ of the development project evaluation criteria

\begin{tabular}{llllllllllll}
\hline Criterion & 1 & 2 & 3 & 4 & 5 & 6 & 7 & 8 & 9 & 10 & 11 \\
\hline 1. Additional offer & 1 & 0.01 & 0.23 & 0.30 & -0.13 & -0.24 & 0.18 & 0.18 & -0.15 & 0.21 & -0.24 \\
2. Number of storeys & 0.01 & 1 & 0.18 & 0.22 & -0.24 & -0.19 & 0.12 & -0.24 & -0.41 & 0.05 & -0.41 \\
3. Modishness (trend) & 0.23 & 0.18 & 1 & 0.30 & -0.00 & -0.23 & -0.18 & -0.22 & 0.09 & 0.02 & -0.20 \\
4. Immediate environment & 0.30 & 0.22 & 0.30 & 1 & -0.14 & -0.27 & -0.07 & 0.34 & -0.19 & 0.07 & 0.06 \\
5. Distance from the city centre & -0.13 & -0.24 & -0.00 & -0.14 & 1 & 0.05 & -0.11 & -0.03 & 0.02 & 0.00 & -0.19 \\
6. Building layout & -0.24 & -0.19 & -0.23 & -0.27 & 0.05 & 1 & -0.29 & -0.10 & -0.22 & -0.26 & 0.01 \\
7. Design solutions & 0.18 & 0.12 & -0.18 & -0.07 & -0.11 & -0.29 & 1 & 0.11 & 0.04 & 0.09 & 0.03 \\
8. Housing structure & 0.18 & -0.24 & -0.22 & 0.34 & -0.03 & -0.10 & 0.11 & 1 & -0.21 & 0.12 & 0.10 \\
9. Scheduled execution time ratio & -0.15 & -0.41 & 0.09 & -0.19 & 0.02 & -0.22 & 0.04 & -0.21 & 1 & -0.02 & 0.30 \\
10. Floorage use ratio & 0.21 & 0.05 & 0.02 & 0.07 & 0.00 & -0.26 & 0.09 & 0.12 & -0.02 & 1 \\
11. Land-use ratio & -0.24 & -0.41 & -0.20 & 0.06 & -0.19 & 0.01 & 0.03 & 0.10 & 0.30 & -0.17 & 1 \\
\hline
\end{tabular}



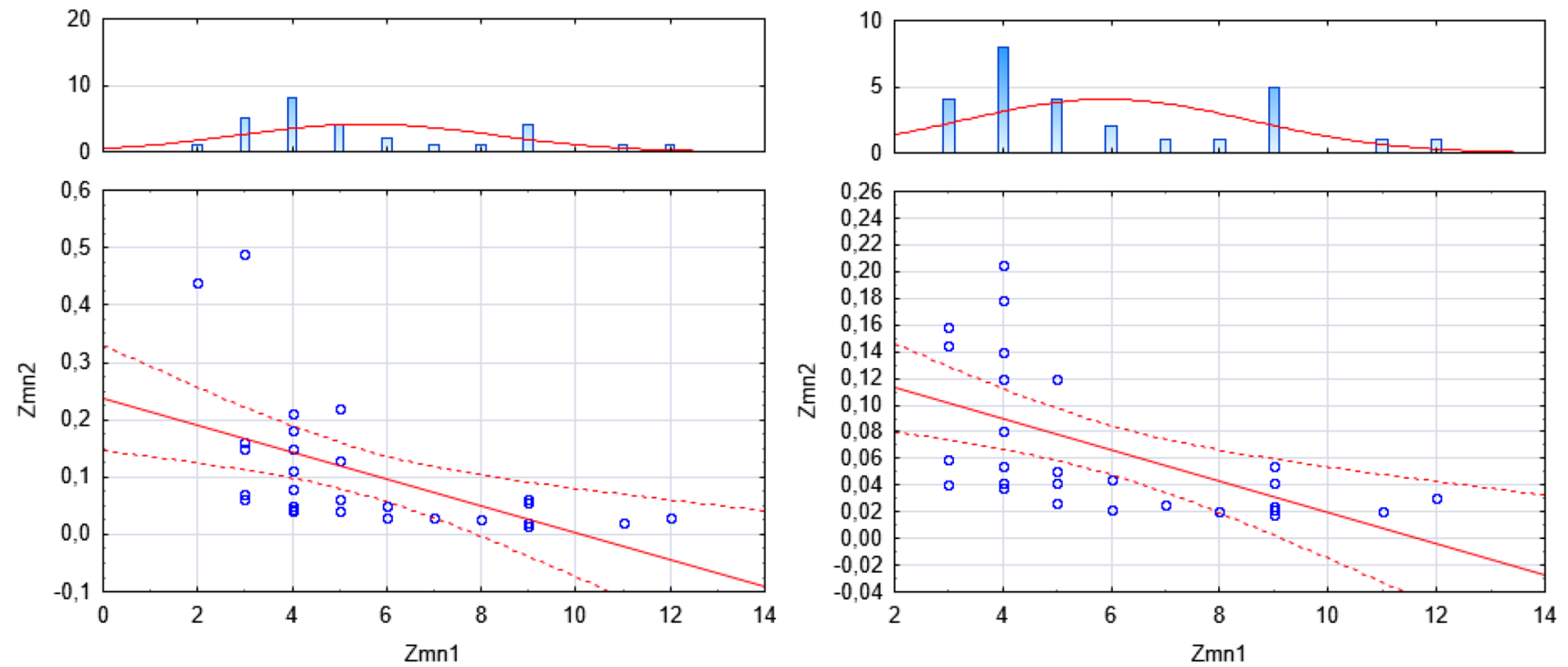

Fig. 5 The scatter diagram for the criteria 2-the number of storeys and 9 -factor $\mathbf{a}$ of the planned pace of construction, $\mathbf{b}$ of the planned pace of construction after the removal of the suspicious value

whose rejection can change the size of the correlation. In the figure, they are marked with red circles.

After removing the two extreme values marked in Fig. 5a, we obtain a new scatter diagram (Fig. 5b) and a change of the correlation coefficient. The result of re-examination after the rejection of extreme values increases the strength of correlation between criteria 2 and 9 by only 0.01 . The effect of the rejected values is small and does not cause an error in the analysis carried out.

\section{Conclusions}

Decisions taken during the planning and preparation of a development project have a crucial impact on its profitability. Lack of proper coordination by the client of the construction process (arrangement and synchronisation of mutual action between the parties, harmonisation of the prevailing relations, coordination of activities related to risk reduction) can lead to a significant prolongation of the duration of the investment, to the build up of problems, conflicts, and even the failure to achieve the intended purpose. The proposed decision support model of assessing a construction project in the housing sector makes it possible to compare and evaluate different variants based on 11 factors identified. Using the analysis of main components, 11 variables describing the observations were checked. In the area of research, the nature of the relationship and the importance of the impact of the project's individual characteristics on the global assessment of the project were evaluated.
The use of fuzzy logic in the model has enabled more accurate description of the phenomenon analysed when the exact parameters of the project in the planning and preparation stage of the project are not known. Knowledge of the factors and their characteristics affecting the profitability of the project undertaken is essential for effective planning and preparing of the development project. There is a need to create professional tools for clients to support investment decision-making. This article presents a proposal for an algorithm supporting the evaluation of development projects.

Open Access This article is distributed under the terms of the Creative Commons Attribution 4.0 International License (http:// creativecommons.org/licenses/by/4.0/), which permits unrestricted use, distribution, and reproduction in any medium, provided you give appropriate credit to the original author(s) and the source, provide a link to the Creative Commons license, and indicate if changes were made.

\section{References}

1. Yong YC, Mustaffa NE (2012) Analysis of factors critical to construction project success in Malaysia. Eng Constr Archit Manag 19(5):543-556

2. Takim R, Adnan H (2008) Analysis of effectiveness measures of construction project success in Malaysia. Asian Soc Sci 4(7):74-91

3. Atkinson R (1999) Project management: cost, time and quality, two best guesses and a phenomenon, its time to accept other success criteria Int J Project Manag 17(6):337-342 
4. Crawford P, Bryce P (2003) Project monitoring and evaluation: a method for enhancing the efficiency and effectiveness of aid project implementation. Int J Project Manag 21(5):363-373

5. Abdel-Razek RH (1997) How construction managers would like their performance to be evaluated. J Constr Eng Manag 123(3):208-213

6. Smith M (1998) Measuring organisational effectiveness. Manag Acc 76(9):34-36

7. Nyhan RC, Martin LL (1999) Comparative performance measurement. Public Prod Manag Rev 22(3):348-364

8. Dadpour M, Shakeri E (2016) Improving strategies of the private sector participation in water sector projects: a case study in Ministry of Energy (Iran). Int J Civ Eng 14(1):61-73

9. Akintoye A (2000) Analysis of factors influencing project cost estimating practice. Constr Manag Econ 18(1):77-89

10. An S, Cho H, Lee U (2011) Reliability assessment of conceptual cost estimates for building construction projects. Int J Civ Eng 9(1):9-16

11. Plebankiewicz E, Lesniak A (2013) Overhead costs and profit calculation by polish contractors. Technol Econ Dev Econ 19(1):141-161

12. Thomas Ng S, Fan R, Wong J (2011) An econometric model for forecasting private construction investment in Hong Kong. Constr Manag Econ 29(5):519-534

13. Ustinovichius L, Zavadskas EK, Podvezko V (2007) Application of a quantitative multiple criteria decision making (MCDM-1) approach to the analysis of investments in construction. Control Cybern 36(1):251-268

14. Zavadskas EK, Ustinovichius L, Stasiulionis A (2004) Multicriteria valuation of commercial construction projects for investment purposes. J Civ Eng Manag X(2):151-166

15. Šarka V, Šarkienė E, Budinas S (2005) Model of investment evaluation of public building based on multiple criteria decision synthesis methods. In: Proceedings of the 5th international conference RelStat'04, transport and telecommunication 6(1):172-182
16. Ustinovichius L, Šarkienė E (2006) The analysis of apartment house construction investments efficiency applying mathematical modelling. In: Proceedings of the 5th international conference RelStat'05, transport and telecommunication 7(1):97-105

17. Zadeh LA (1965) Fuzzy sets. Inf Control 8:338-353

18. Baas SM, Kwakernaak H (1977) Rating and raking of multiple-aspects alternatives using fuzzy sets. Automatica 13:47-58

19. Guneri AF, Cengiz M, Seker S (2009) A fuzzy ANP approach to shipyard location selection. Expert Syst Appl 36(4):7992-7999

20. Zima K (1738) Fuzzy case based reasoning in sports facilities unit cost estimating, 2016. AIP Conf. Proc. 200008

21. Kaveh A, Khanzadi M, Alipour M (2016) Fuzzy resource constraint project scheduling problem using $\mathrm{CBO}$ and CSS algorithms. Int J Civ Eng 14(5):325-337

22. Plebankiewicz E, Zima K, Wieczorek D (2016) Life cycle cost modelling of buildings with consideration of the risk. Arch Civ Eng 62(2):149-166

23. Minasowicz A (2009) Feasibility study of construction investment projects assessment with regard to risk and probability of NPV reaching. Org Technol Manag Constr Int J 1(1):10-14

24. Chen J-H (2012) A hybrid knowledge-sharing model for corporate foreign investment in China's construction market. Expert Syst Appl 39(9):7585-7590

25. Nasirzadeh F, Mazandaranizadeh H, Rouhparvar M (2016) Quantitative risk allocation in construction projects using cooperative-bargaining game theory. Int J Civ Eng 14(3):161-170

26. Nasirzadeh F, Khanzadi M, Afshar A, Howick S (2013) Modeling quality management in construction projects. Int J Civ Eng 11(1):14-22

27. Koo CW, Park SH, Yi JS, Kwon OK (2013) Development of web-based design management system through user participatory design and use-case modeling. Int J Civ Eng 11(1):23-32

28. Zima K (2013) The concept of investment decision support model using fuzzy set theory. AIP Conf Proc 1558(1307):1307-1311 